\title{
Foreword
}

\section{Management of infections in pediatric critical care}

\author{
Scott L. Weiss* and Julie C. Fitzgerald \\ Department of Anesthesia and Critical Care, The Children's Hospital of Philadelphia, University of Pennsylvania \\ Perelman School of Medicine, Philadelphia, PA, USA
}

Received 20 December 2014

Accepted 20 December 2014

In this special issue of the Journal of Pediatric Intensive Care, we have compiled a series of articles addressing the management of infections in critically ill children. Directed antimicrobial treatment and concurrent supportive care are key aspects of pediatric critical care. According to the World Health Organization, in 2013, approximately $50 \%$ of all childhood deaths worldwide were caused by the combination of bacterial, viral, fungal, and parasitic infections [1]. The development of a systemic inflammatory response to an invasive infection defines the sepsis syndrome and sepsis remains the leading cause of multiple organ dysfunction in the pediatric intensive care unit (PICU) $[2,3]$. Recent estimates suggest that over one-third of children who die in the PICU suffer from sepsis [4]. Perhaps most worrisome is that the overall prevalence of severe sepsis and septic shock appears to be rising, likely reflecting an expanding vulnerable population with acute and chronic comorbid conditions and increasing rates of multi-drug resistant organisms and opportunistic infections [4-12]

With the current ease of international travel, pediatric intensivists working in both developed and

\footnotetext{
*Corresponding author: Scott L. Weiss, MD, MSCE, Department of Anesthesia and Critical Care, The Children's Hospital of Philadelphia, University of Pennsylvania Perelman School of Medicine, Philadelphia, PA 19104, USA. Tel.: +1 215590 2356; Fax: +1 215 590 4327; E-mail: WeissS@email.chop.edu.
}

developing countries need to be well-versed in the management of a wide variety of infections that can lead to critical illness. We have therefore chosen to select articles that address a broad range of infectious topics, including basic and advanced management considerations applicable for pediatric intensivists worldwide.

In the first article, directed antibiotic therapy against common bacterial causes of sepsis is reviewed by organism and site of infection. Several studies in adults, and increasingly in pediatrics, have demonstrated that early antibiotic therapy improves outcomes in bacterial sepsis [13-16]. However, these benefits rely on appropriate empiric antibiotic selection which requires attention to the most likely bacterial pathogens affecting a given patient [17]. The second and third articles review adjunctive and novel therapies for pediatric septic shock, including consideration for sepsis/hemophagocytic lymphohistiocytosis/ macrophage activating syndrome overlap that is characterized by hyperferritinemia, persistent cytopenias, and evidence for uncontrolled systemic inflammation.

In the fourth article, the management of common and severe viral infections is reviewed. Although targeted management remains limited for most viral infections, several pathogens may be amenable to specific therapies and the approach to supportive care can also vary 
between different viral syndromes. Considerations for treating patients during seasonal influenza outbreaks, as well as the role of the pediatric intensivist during global pandemics, is addressed in the fifth article. Bacterial co-infection in children with an underlying viral syndrome presents a particularly important challenge as diagnostic tests lack necessary sensitivity and specificity. However, given the significant adverse impact of bacterial co-infection, particularly Staphylococcus aureus, on morbidity and mortality in the PICU [18], antibiotic management strategies are reviewed for patients with influenza and other viral syndromes.

The management of invasive fungal infections, parasitic diseases and special considerations for patients with immune compromise are each reviewed in a dedicated article. The most common invasive fungal infection seen in critically ill children is invasive candidiasis, and this is the main focus of the sixth article. Empiric, preemptive and definitive therapy for invasive candidiasis is reviewed, and recommendations for evaluation of disseminated candidiasis are provided. Severe manifestations of parasitic infections necessitating intensive care are discussed in the review of parasitic diseases. The epidemiology, presentation and diagnosis, treatment, and prevention of malaria, neurocysticercosis, Strongyloides, Chagas disease, baylisascariasis, and amoebic meningoencephalitis are reviewed. In the eighth article, management of infections in the immunocompromised host is reviewed, including host factors, key diagnostic considerations, and management of bloodstream and pulmonary infections.

The final article addresses the management of children with healthcare-associated infections (HAIs), an increasing, costly, and largely preventable problem in hospitals and PICUs across the world [19-21]. This review addresses common HAIs, including central line-associated bloodstream infections, catheter-associated urinary tract infections, ventilatorassociated events and nosocomial viral infections. For each problem, recommendations for targeted management are provided, in addition to strategies to prevent and reduce the occurrence of HAIs.

Despite important public health advances over the last century, including improved sanitation, clean drinking water, peri-partum antimicrobial prophylaxis, and access to growing repertoire of vaccines, we will always share our world with a wide variety of microorganisms whose only evolutionary goal is to infect and reproduce. The management of bacterial, viral, fungal and parasitic infections will therefore remain a cornerstone of the care that we provide as pediatric intensivists. The compilation of articles in this issue of the Journal of Pediatric Intensive Care provides an important overview of the complex management strategies necessary to restore the health of our world's most previous resource-our children.

\section{References}

[1] World Health Organization, Child mortality and causes of death, 2013. Available at: http://www.who.int/gho/child_ health/mortality/causes/en/. Accessed December 16, 2014.

[2] Goldstein B, Giroir B, Randolph A; International Consensus Conference on Pediatric Sepsis. International pediatric sepsis consensus conference: Definitions for sepsis and organ dysfunction in pediatrics. Pediatr Crit Care Med 2005;6(1):2-8.

[3] Proulx F, Joyal JS, Mariscalco MM, Leteurtre S, Leclerc F, Lacroix J. The pediatric multiple organ dysfunction syndrome. Pediatr Crit Care Med 2009;10(1):12-22.

[4] Ruth A, McCracken CE, Fortenberry JD, Hall M, Simon HK, Hebbar KB. Pediatric severe sepsis: Current trends and outcomes from the Pediatric Health Information Systems database. Pediatr Crit Care Med 2014;15(9):828-38.

[5] Balamuth B, Weiss SL, Neuman MI, Scott H, Brady PW, Paul $\mathrm{R}$, et al. Pediatric severe sepsis in US children's hospitals: Longitudinal trends and impact of coding strategy. Pediatr Crit Care Med 2014;15(9):798-805.

[6] Hartman ME, Linde-Zwirble WT, Angus DC, Watson RS Trends in the epidemiology of pediatric severe sepsis. Pediatr Crit Care Med 2013;14(7):686-93.

[7] Howlader N, Noone AM, Krapcho M, Garshell J, Miller D, Altekruse SF, et al. National cancer Institute. Surveillance, Epidemiology, and End Results Program (SEER), Cancer Statistics Review 1975-2011, 2014. Available at: http://seer.cancer.gov/csr/1975_2011/. Accessed December $15,2014$.

[8] Magee JC, Krishnan SM, Benfield MR, Hsu DT, Shneider BL. Pediatric transplantation in the United States, 1997-2006. Am J Transplant 2008;8(4 Pt 2):935-45.

[9] Wen SW, Smith G, Yang Q, Walker M. Epidemiology of preterm birth and neonatal outcome. Semin Fetal Neonatal Med 2004;9(6):429-35.

[10] Gudiol C, Bodro M, Simonetti A, Tubau F, González-Barca $\mathrm{E}$, Cisnal $\mathrm{M}$, et al. Changing aetiology, clinical features, antimicrobial resistance, and outcomes of bloodstream infection in neutropenic cancer patients. Clin Microbiol Infect 2013;19(5):474-9.

[11] Kunz AN, Brook I. Emerging resistant Gram-negative aerobic bacilli in hospital-acquired infections. Chemotherapy 2010;56(6):492-500.

[12] Hufnagel M, Burger A, Bartelt S, Henneke P, Berner R. Secular trends in pediatric bloodstream infections over a 20 -year period at a tertiary care hospital in Germany. Eur J Pediatr 2008;167(10):1149-59.

[13] Kumar A, Roberts D, Wood KE, Light B, Parrillo JE, Sharma $S$, et al. Duration of hypotension before initiation of effective antimicrobial therapy is the critical determinant of survival in human septic shock. Crit Care Med 2006;34(6):1589-96. 
[14] Puskarich MA, Trzeciak S, Shapiro NI, Arnold RC, Horton JM, Studnek JR, et al.; Emergency Medicine Shock Research Network (EMSHOCKNET). Association between timing of antibiotic administration and mortality from septic shock in patients treated with a quantitative resuscitation protocol. Crit Care Med 2011;39(9):2066-71

[15] Weiss SL, Fitzgerald JC, Balamuth F, Alpern ER, Lavelle J, Chilutti M, et al. Delayed antimicrobial therapy increases mortality and organ dysfunction duration in pediatric sepsis. Crit Care Med 2014;42(11):2409-17.

[16] Ferrer R, Martin-Loeches I, Phillips G, Osborn TM, Townsend S, Dellinger RP, et al. Empiric antibiotic treatment reduces mortality in severe sepsis and septic shock from the first hour: Results from a guideline-based performance improvement program. Crit Care Med 2014;42(8):1749-55.

[17] Gaieski DF, Mikkelsen ME, Band RA, Pines JM, Massone $\mathrm{R}$, Furia FF, et al. Impact of time to antibiotics on survival in patients with severe sepsis or septic shock in whom early goaldirected therapy was initiated in the emergency department. Crit Care Med 2010;38(4):1045-53.
[18] Randolph AG, Vaughn F, Sullivan R, Rubinson L, Thompson BT, Yoon G, et al.; Pediatric Acute Lung Injury and Sepsis Investigator's Network and the National Heart, Lung, and Blood Institute ARDS Clinical Trials Network. Critically ill children during the 2009-2010 influenza pandemic in the United States. Pediatrics 2011;128(6):e1450-8.

[19] Magill SS, Edwards JR, Bamberg W, Beldavs ZG, Dumyati G, Kainer MA, et al.; Emerging Infections Program HealthcareAssociated Infections and Antimicrobial Use Prevalence Survey Team. Multistate point-prevalence survey of health care-associated infections. N Engl J Med 2014;370(13):1198208.

[20] Kuzdan C, Soysal A, Culha G, Altinkanat G, Soyletir G, Bakir M. Three-year study of health care-associated infections in a Turkish pediatric ward. J Infect Dev Ctries 2014;8(11):141520.

[21] Ndegwa LK, Katz MA, McCormick K, Nganga Z, Mungai A, Emukule G, et al. Surveillance for respiratory health careassociated infections among inpatients in 3 Kenyan hospitals, 2010-2012. Am J Infect Control 2014;42(9):985-90. 